\title{
JENIS DAN KEPADATAN REKRUITMEN KARANG BERDASARKAN BENTUK PERTUMBUHAN KARANG SCLERACTINIA DI PERAIRAN DESA LALANU KABUPATEN KONAWE SULAWESI TENGGARA
}

\section{Type and Density of Coral Recruitment Based on Scleractinian Coral Life Form in Lalanu Waters Konawe Regency Southeast Sulawesi}

\author{
Karmila $^{1}$, Baru Sadarun ${ }^{2}$, dan Rahmadani ${ }^{3}$ \\ ${ }^{1}$ Mahasiswa Jurusan Ilmu Kelautan, \\ Fakultas Perikanan dan Ilmu Kelautan, Universitas Halu Oleo. \\ Jl. H.E.A Mokodompit Kampus Hijau Bumi Tridharma Anduonohu Kendari 93232, Telp/Fax: (0401) 3193782 \\ ${ }^{2}$ Surel: sadarunbaru6@gmail.com \\ ${ }^{3}$ Surel: rahmamustafa47@gmail.com
}

\begin{abstract}
Abstrak
Rekrutmen karang adalah faktor penting dalam menjaga stabilitas keberadaan terumbu karang dan dalam pemulihan setelah adanya gangguan substansial. Penelitian ini bertujuan untuk mengetahui jenis dan kepadatan rekruitmen karang berdasarkan bentuk pertumbuhan karang Scleractinia di perairan Lalanu. Pengambilan sampel rekruitmen karang dilakukan dengan menggunakan metode Belt Transek (transek sabuk) yang berukuran $200 \mathrm{~m}^{2}$. Transek sabuk dipasang sejajar garis pantai. Jenis dan jumlah individu karang baru didata yang berada di dalam transek tersebut. Diperoleh 6 jenis rekruitmen karang berdasarkan bentuk pertumbuhan yang diperoleh di lokasi penelitian yaitu Coral mushroom (CMR), Coral Massive (CM), Coral Branching (CB), Acropora Branching (ACB), Coral folliose (CF),dan Coral Encrustig (ACE). Kepadatan rekrutmen karang tertinggi terdapat pada stasiun I yaitu $0,2 \mathrm{ind} / \mathrm{m}^{2}$ dan terendah ditemukan pada stasiun III sebanyak $0,16 \mathrm{ind} / \mathrm{m}^{2}$. Rekruitmen karang berdasarkan bentuk pertumbuhan yang ditemukan di semua stasiun (frekuensi kemunculan 100\%) adalah Acropora Branching (ACB), Coral Massive (CM), dan Coral folliose (CF).
\end{abstract}

Kata Kunci : Karang scleractinia, rekruitmen karang, kepadatan, Perairan Lalanu

\begin{abstract}
Coral recruitment is a pivotal factor in coral reef stability and in recovery following substantial disturbances. This study aimed to investigate the type and density of coral recruitment based on lifeform of Scleractinian in Lalanu seawaters. Belt transect method measuring $200 \mathrm{~m}^{2}$ was applied to observe coral precruitment placed parallel to the shoreline. The types and number of new coral individuals were recorded at the transect area. Six types of coral recruitment were recorded based on the lifeform at the study sites, namely Coral Mushroom (CMR), Coral Massive (CM), Coral Branching (CB), Acropora Branching (ACB), Coral folliose (CF), and Coral Encrustig (ACE). The highest density of coral recruitment was found at station I achieved $0.2 \mathrm{ind} / \mathrm{m} 2$ and the lowest was found at station III with $0.16 \mathrm{ind} / \mathrm{m} 2$. Coral recruitments based on lifeform which found with $100 \%$ occurrence frequency in all sites were Acropora Branching (ACB), Coral Massive (CM), and Coral folliose (CF).
\end{abstract}

Keywords: Scleractinian, coral recruitment, density, Lalanu Seawaters

\section{Pendahuluan}

Terumbu karang saat ini menghadapi tekanan dan ancaman kombinasi dari alam, eksploitasi yang berlebihan, polusi dan khususnya perubahan iklim dunia yang kesemua ancaman tersebut saat ini meningkat jumlahnya. Para ilmuwan berpendapat persentase tutupan karang sclereractinia yang hidup mengalami penurunan drastis setiap tahunnya yang salah satu faktor utamanya yakni bencana alam, aktivitas industri dan aktivitas manusia.

Rekruitmen karang merupakan masuknya individu karang baru ke populasi karang karena reproduksi atau migrasi. Proses rekruitmen berperan dalam penambahan individu-individu baru kedalam populasi dewasa sehingga eksistensi dan keberlanjutan populasi dapat dipertahankan dan berlangsung secara terus menerus (Erwinet al., 2008).

Perairan Lalanu merupakan salah satu wilayah yang berdekatan dengan daerah yang menjadi tujuan wisata Pantai, perairan tersebut banyak dikunjungi oleh masyarakat baik untuk berenang, snorkeling atau hanya menikmati pemandangan alam. Perairan tersebut juga dijadikan sebagai daerah penangkapan ikan oleh masyarakat karena perairan tersebut memiliki karang yang cukup luas. 
Tujuan penelitian ini adalah untuk mengetahui jenis dan kepadatan rekruitmen karang berdasarkan bentuk pertumbuhan karang Scleractinia yang ada di perairan Lalanu. Kegunaan dari penelitian ini adalah dapat menjadi data awal untuk jenis-jenis rekruitmen karang serta menjadi acuan pembaca mengenai rekruitmen karang di perairan Lalanu.

\section{Bahan dan Metode}

Penelitian ini dilakukan pada Bulan September 2018, bertempat di perairan Lalanu, Kecamatan Soropia, Kabupaten Konawe, Provinsi Sulawesi Tenggara.

Survei pendahuluan bertujuan untuk mengetahui keberadaan karang baru pada lokasi penelitian. Pengamatan dilakukan dengan menggunakan alat dasar selam dengan cara snorkeling sampai dengan ditemukan karang rekrut. Survey ini bertujuan untuk melihat kondisi awal lokasi penelitian. Kondisi awal yang ada dilokasi penelitian sangat berpengaruh terhadap titik stasiun penelitian sehingga dapat digunakan sebagai dasar penentuan titik lokasi penelitian.

Setelah melakukan survei pendahuluan, dilakukan penandaan stasiun penelitian menggunakan GPS untuk menandai titik stasiun penelitian. Penentuan lokasi stasiun berdasarkan metode purposive sampling yang berdasarkan pertimbangan keberadaan karang di lokasi penelitian. Stasiun penelitian di perairan Lalanu terdiri dari 3 titik stasiun yang terdiri dari :

a. Stasiun I : Terletak pada $3^{\circ} 53^{\prime} 18.90 " L S$ dan $122^{\circ} 36^{\prime} 46.59^{\prime \prime B T}$ yang terletak di sebelah Timur, dimana perairan tersebut langsung berhadapan dengan laut lepas yanng mempunyai perairan yang jernih dan sebagai tempat penangkapan ikan oleh masyarakat.

b. Stasiun II : Terletak pada $3^{\circ} 53^{\prime} 18.59^{\prime \prime} \mathrm{LS}$ dan $122^{\circ} 36^{\prime} 57.68^{\prime \prime B T}$ yang terletak di sebelah barat perairan Desa Lalanu, yang mempunyai peraairan yang jernih.

c. Stasiun III : Terletak pada $3^{\circ} 53^{\prime} 20.41^{\prime \prime L S}$ dan $122^{\circ} 37^{\prime} 4.69^{\prime \prime}$ BT yang terletak didekat aliran sungai.

Pengambilan sampel rekruitmen karang dilakukan dengan menggunakan metode Belt Transek (transek sabuk) berukuran $200 \quad \mathrm{~m}^{2}$. Transek sabuk dipasang sejajar garis pantai. Selanjutnya didata jenis dan jumlah individu karang baru berdasarkan bentuk pertumbuhan karang yang berada di dalam transek tersebut.

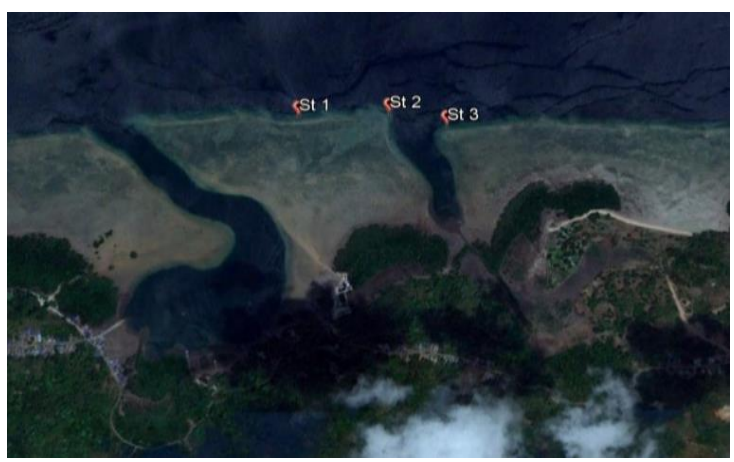

Gambar 1. Sketsa Lokasi Penelitian (Google Earth, 2018)

Identifikasi dilakukan dengan cara mendata jenis karang yang berukuran kurang dari $5 \mathrm{~cm}$ dari tiap genus dari ordo Scleractinia yang ditemukan dengan menggunakan pengamatan deskriptif visual dengan bantuan kamera untuk identifikasi jenis karang rekrut yang ada di lokasi penelitian. Perhitungan juga dibantu dengan alat hand counter yaitu untuk menghitung individu karang rekrut yang ada pada tiap stasiun.

Pengukuran data pendukung penelitan berupa suhu, salinitas, kecerahan, dan kecepatan arus. Pengukuran ini dilakukan pada tiap stasiun penelitian dan dilakukan langsung (in situ) selama pengambilan data utama penelitian. Alat yang digunakan untuk pengukuran dapat dilihat pada Tabel 1.

\section{Analisis Data}

Analisis data hasil penelitian dilakukan dengan menggunakan analisis deskriptif dengan bantuan gambar dan grafik. Jenis karang baru juga ditunjang dengan dokumentasi berupa foto.

Kepadatan dapat dihitung dengan menggunakan rumus Odum (1971) sebagai berikut :

$\mathrm{N}=\frac{\mathrm{ni}}{\mathrm{A}}$

Keterangan :

$\mathrm{N}=$ kepadatan karang rekrut $\left(\right.$ Koloni $\left./ \mathrm{cm}^{2}\right)$

$\mathrm{ni}=$ jumlah koloni karang genus ke-i

$\mathrm{A}=$ luas pengambilan sampel $\left(\mathrm{m}^{2}\right)$ 
Komposisi jenis ditentukan dengan perhitungan jumlah spesies dan jumlah individu pada setiap spesies serta proporsinya (Odum, 1996), dengan rumus:

$\mathbf{P i}=\frac{n i}{N} \times 100 \%$

dengan:

$\mathrm{n}_{\mathrm{i}}=$ Jumlah individu jenis ke- $\mathrm{i}$

$\mathrm{N}=$ Jumlah total individu.

Perhitungan frekuensi kemunculan setiap jenis rekruitmen karang digunakan rumus sebagai berikut (Odum, 1971):

$F=\frac{\sum M}{\sum S t} \times 100 \%$

Keterangan :

$\mathrm{F}$ : Frekuensi kemunculan setiap jenis karang $\Sigma \mathrm{M}$ : Jumlah kemunculan pada setiap stasiun $\Sigma$ St : Jumlah stasiun

\section{Hasil dan Pembahasan}

Rekruitmen karang dengan pertumbuhan ACB ditemukan dengan jumlah total 24 koloni. Sebanyak 7 koloni ditemukan di Stasiun I, di Stasiun II ditemukan 9 koloni, 8 koloni ditemukan pada Stasiun III. Bentuk pertumbuhan Acropora branching ditemukan pada semua stasiun penelitian. Bentuk pertumbuhan coral massive ditemukan sebanyak 28 koloni dari semua stasiun penelitian. Sebanyak 5 koloni ditemukan pada stasiun I, 11 koloni pada stasiun II dan 12 koloni pada stasiun III. Bentuk pertumbuhan coral folliose ditemukan sebanyak 28 koloni dari semua stasiun penelitian. Sebanyak 12 koloni ditemukan pada stasiun I, 6 koloni pada stasiun II dan 10 koloni pada stasiun III. Bentuk pertumbuhan coral mushroom ditemukan sebanyak 12 koloni yang ditemukan pada stasiun I dan II, sedangkan pada stasiun III tidak ditemukan bentuk pertumbuhan karang mushroom. Bentuk pertumbuhan coral encrusting ditemukan sebanyak 6 koloni dan hanya ditemukan pada stasiun I. Bentuk pertumbuhan coral braching ditemukan sebanyak 10 koloni dari semua stasiun penelitian. Sebanyak 2 koloni ditemukan pada stasiun I, 6 koloni pada stasiun II dan 2 koloni pada stasiun III.

Bentuk pertumbuhan yang dapat ditemui di seluruh stasiun adalah acropora branching, coral folliose, coral massive dan coral branching. Bentuk pertumbuhan yang jumlah koloninya paling banyak adalah brancing sedangkan yang jumlah koloninya paling sedikit adalah branching.

Menurut Veron (1995), setiap jenis karang mempunyai respon yang spesifik terhadap karakteristik lingkungannya. Faktor lingkungan, seperti kedalaman, kuat arus dan gelombang dapat mempengaruhi bentuk pertumbuhan karang. Bentuk pertumbuhan karang batu umumnya merupakan refleksi dari kondisi lingkungan di sekitarnya, contohnya spesies karang dengan bentuk percabangan dan pertumbuhan yang ramping umumnya terdapat pada stasiun dengan energi gelombang yang rendah (Riegl et al. 1996).
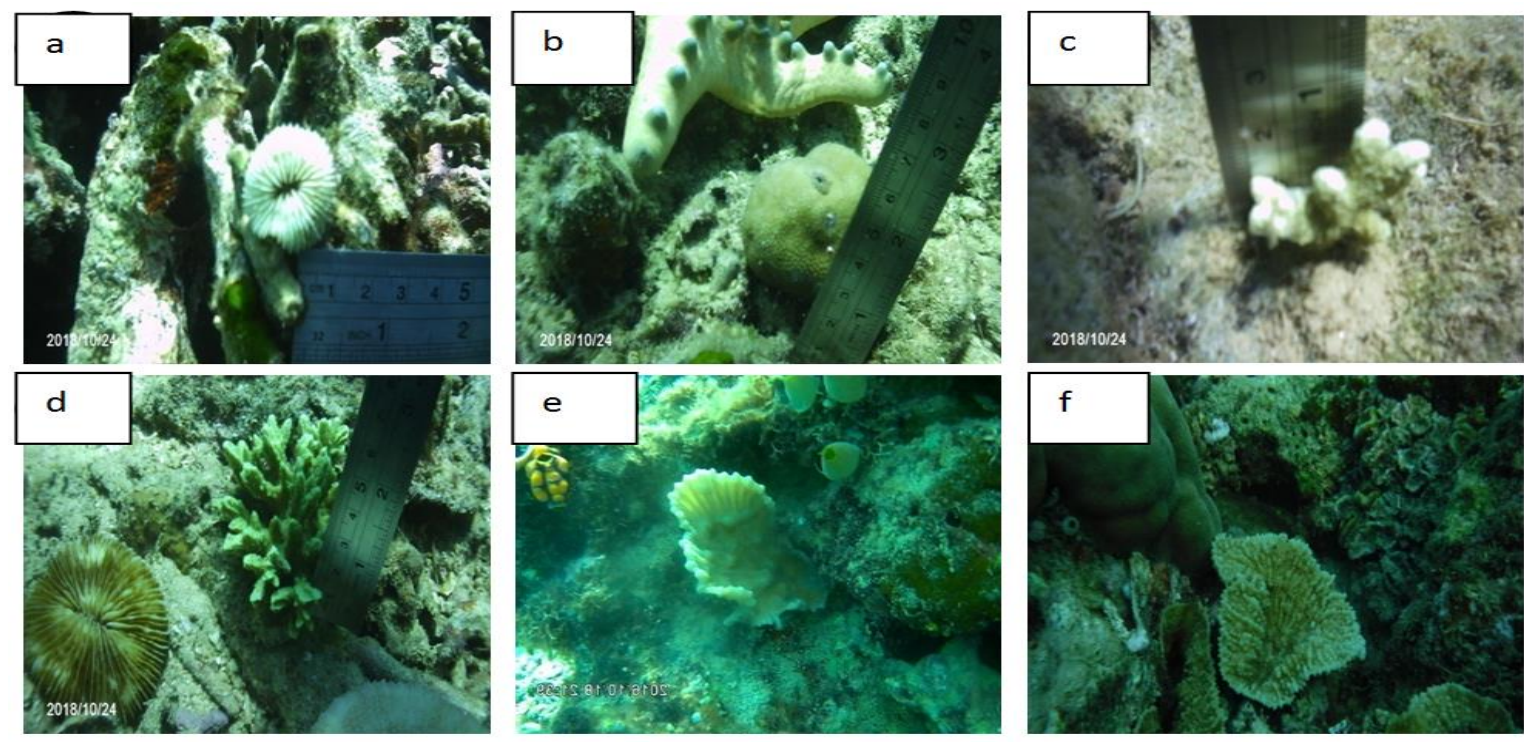

Gambar 2. Hasil penelitian rekruitmen karang berdasarkan bentuk pertumbuhan (a. Coral mushroom (CMR); b. Coral Massive (CM); c. Coral Branching (CB); d. Acropora Branching (ACB); e. Coral folliose (CF); f.Coral Encrustig (ACE) 
Tabel 1. Kepadatan rekruitmen karang berdasarkan bentuk pertumbuhan karang

\begin{tabular}{|c|c|c|c|c|c|c|}
\hline \multirow{2}{*}{ Stasiun } & \multirow{2}{*}{$\begin{array}{c}\text { Bentuk } \\
\text { pertumbuhan } \\
\text { karang }\end{array}$} & \multicolumn{2}{|c|}{ Pengulangan } & \multirow{2}{*}{$\begin{array}{c}\text { Jumlah } \\
(\mathbf{N i})\end{array}$} & \multirow{2}{*}{$\begin{array}{c}n=n i / A \\
\text { (ind/ } / \mathbf{m}^{2} \text { ) }\end{array}$} & \multirow{2}{*}{ Total } \\
\hline & & I & II & & & \\
\hline \multirow{6}{*}{ I } & $\mathrm{ACB}$ & 3 & 4 & 7 & 0,035 & \multirow{6}{*}{0,2} \\
\hline & $\mathrm{CM}$ & 2 & 3 & 5 & 0,025 & \\
\hline & $\mathrm{CF}$ & 3 & 9 & 12 & 0,06 & \\
\hline & $\mathrm{ACE}$ & 2 & 4 & 6 & 0,03 & \\
\hline & $\mathrm{CB}$ & 1 & 1 & 2 & 0,01 & \\
\hline & CMR & 2 & 6 & 8 & 0,04 & \\
\hline \multirow{5}{*}{ II } & $\mathrm{ACB}$ & 4 & 5 & 9 & 0,045 & \multirow{5}{*}{0,19} \\
\hline & $\mathrm{CM}$ & 7 & 4 & 11 & 0,055 & \\
\hline & $\mathrm{CB}$ & 2 & 4 & 6 & 0,03 & \\
\hline & $\mathrm{CF}$ & 3 & 3 & 6 & 0,03 & \\
\hline & CMR & 4 & 2 & 6 & 0,03 & \\
\hline \multirow{4}{*}{ III } & $\mathrm{CM}$ & 8 & 4 & 12 & 0,06 & \multirow{4}{*}{0,16} \\
\hline & $\mathrm{ACB}$ & 5 & 3 & 8 & 004 & \\
\hline & $\mathrm{CB}$ & - & 2 & 2 & 0,01 & \\
\hline & $\mathrm{CF}$ & 4 & 6 & 10 & 0,05 & \\
\hline
\end{tabular}

Acosta et al. (2011) yang menyebutkan bahwa planula karang lebih cenderung melekat dan membentuk rekruitmen baru pada substrat yang stabil. Hal tersebut ditujukan untuk memperkecil kemungkinan kematian akibat terjangan arus dan gelombang.

Menurut Bauman (2015) tipe substrat dasar perairan berhubungan langsung terhadap pertumbuhan terumbu karang sejak proses penempelan. Substrat keras diperlukan untuk melekat larva karang yang akan membetuk koloni baru. Pertumbuhan koloni karang mengarah ke atas dan ke samping, sehingga lama kelamaan akan mengisi kolom perairan. Dasar perairan yang bersubstrat bebatuan sering kali digunakan untuk penempelan awal larva karang.

Kepadatan rekruitmen karang beradasarkan bentuk pertumbuhan karang tertinggi terdapat pada stasiun I yaitu sebesar $0,2 \mathrm{koloni} / \mathrm{m}^{2}$, kepadatan sedang terdapat pada stasiun II sebesar 0,19 koloni $/ \mathrm{m}^{2}$ dan kepadatan terendah terdapat pada stasiun III yaitu sebesar $0,16 \mathrm{koloni} / \mathrm{m}^{2}$ (Tabel 2). Kepadatan rekruitmen karang bervariasi pada setiap lokasi penelitian. Kepadatan tertinggi ditemukan pada stasiun I dengan bentuk pertumbuhan CF dengan jumlah sebanyak $0,06 \mathrm{ind} / \mathrm{m}^{2}$. Hal ini disebabkan pada stasiun I mempunyai kondisi perairan yang baik untuk pertumbuhan karang. Kepadatan terendah ditemukan pada bentuk pertumbuhan CB yang ditemukan pada stasiun I dan III sebanyak $0,01 \mathrm{ind} / \mathrm{m}^{2}$. Hal ini dikarenakan pada stasiun I dan III mempunyai gelombang yang besar sehingga karang dengan bentuk pertumbuhan CB sulit untuk beradapatasi terhadap lingkungan tersebut, sehingga pergerakan planula untuk menempel pada substrat akan terhambat. Hal ini, sesuai dengan pernayatan (Supriharyono, 2000) yang menyatakan bahwa pergerakan planula untuk berdaptasi pada lingkungan tersebut yaitu dengan melakukan perlindungan terhadap ancaman gelombang dan arus yang besar.

Penelitian kepadatan rekruitmen telah banyak dilakukann dibeberapa perairan Indonesia, antara lain di Pulau Pari (Suharsono, 1995), Kepulauan`Mentawai, Sumatra Barat (Abrar, 2000; 2005), Pulau Lombok dan Nusa Tenggara Timur (Bachtiar, 2002; Bachtiar et al., 2012), di perairan Padang, Sumatra Barat (Zakaria, 2004), di Kepulauan Seribu (Rudi, 2006), di Karimun Jawa (Munasik et al., 2008), di perairan Pulau Panjang, Nias, Sumatra Utara (Siringoringo, 2009) dan di perairan Wakatobi (de-Leon et al., 2013).

Perbedaan kepadatan rekruitmen karang pada setiap stasiun di sebabkan oleh habitat atau substrat yang ada di lokasi penelitian. Ini sesuai dengan pernyatan (Hughes et al., 2002; Glassom et al., 2004, 2006) yang menyatakan bahwa perbedaan kepadatan rekruitmen 
karang dapat terjadi karena perbedaan pengamatan pada habitat (substrat buatan atau alami).

Berdasarkan hasil dari pengamatan pada lokasi penelitian, jumlah bentuk pertumbuhan karang yang ditemukan ditiap stasiun dengan lifeform Acropora branching (ACB), Coral mushroom (CMR), Coral Massive (CM), Coral Branching (CB), Acropora Branching (ACB), Coral folliose (CF) dan Coral Encrustig (ACE) (Tabel 3), termasuk ke dalam golongan Acropora dan non-acropora. menurut (Suharsono, 1984) karang Acropora merupakan karang keras fast growth species (spesies dengan kecepatan pertumbuhan tinggi) yang pertumbuhannya mencapai $15 \mathrm{~cm} /$ tahun, akan tetapi karang ini juga cepat rusak karena struktur kerangkanya yang rapuh dan tidak tahan terhadap tekanan lingkungan seperti arus, gelombang, dan sedimentasi yang tinggi. Sedangkan pada karang Non Acropora yang ditemukan yaitu, Coral encrusting (ACE), Coral massive (CM), dan Coral branching (CB)

Menurut (Suharsono, 1984) karang non- Acropora merupakan karang keras low growth species (spesies dengan kecepatan pertumbuhan lambat) yang pertumbuhannya hanya $1 \mathrm{~cm} /$ tahun. Pada stasiun I ditemukan semua jenis pertumbuhan karang yaitu Acropora branching (ACB), Coral mushroom (CMR), Coral Massive (CM), Coral Branching (CB), Acropora Branching (ACB), Coral folliose (CF) dan Coral Encrustig (ACE) ini disebabkan karena pada stasiun I memiliki kondisi perairan yang baik sehingga karang mampu beradaptasi terhadap tekanan lingkungan.

Pada stasiun II jumlah bentuk pertumbuhan karang keras yang ditemukan Acropora branching (ACB), Coral mushroom (CMR), Coral Massive (CM), Coral Branching (CB), Acropora Branching (ACB), dan Coral folliose (CF). Bentuk pertumbuhan karang ACE hanya ditemukan pada stasiun I Sedangkan pada stasiun II tidak ditemukan karang ACE yang termaksud karang non Acropora. Menurut (Rani et.al., 2004) Sebagai fast growing species seharusnya jenis karang Acropora mampu bertahan dan mendominasi terumbu karang di kedalaman 3 meter ke atas. Namun, Penyebab rendahnya pertumbuhan karang Acropora pada stasiun I disebabkan karena kelompok karang Acropora sudah banyak mengalami kerusakan akibat aktivitas manusia. Pada stasiun III jumlah bentuk pertumbuhan yang ditemukan pada karang keras yaitu, Acropora branching (ACB) dan. Sedangkan pada karang non acropora ditemukan Coral Folliose (CF), Coral massive (CM),

Pada stasiun III komposisi bentuk pertumbuhan karang didominasi oleh Coral massive (CM) pada setiap kedalaman. Coral massive (CM) merupakan karang kompak atau biasa juga disebut karang batu, banyaknya bentuk pertumbuhan coral massive $(\mathrm{CM})$ menandakan bahwa pada titik lokasi penelitian mendapat pengaruh kerusakan yang sangat besar dari aktifitas nelayan dan masyarakat di sekitar. Banyaknya Coral massive (CM) juga menandakan bahwa bentuk karang tersebut memiliki toleransi bentuk pertumbuhan yang lebih kuat dibanding dengan bentuk pertumbuhan karang yang lain. Menurut (Purnomo W. P. et.al,.2008) kematian karang dapat disebabkan oleh aspek fisik dan kimiawi, pada aspek fisik kematian atau kerusakan terumbu karang terjadi karena terkena hantaman gelombang besar yang dapat memporak porandakan terumbu karang, sedangkan dari aspek kimiawi adalah adanya polutan dari aktivitas manusia didarat yang menyebabkan eutrofikasi, sedimentasi,polusi serta masuknya air tawar yang berlebihan dari darat karena terjadinya erosi.

Tabel 2. Frekuensi kemunculan rekruitmen karang pada setiap stasiun

\begin{tabular}{cccccc}
\hline No & $\begin{array}{c}\text { Bentuk pertumbuhan } \\
\text { karang }\end{array}$ & $\begin{array}{c}\text { Stasiun } \\
\text { I }\end{array}$ & $\begin{array}{c}\text { Stasiun } \\
\text { II }\end{array}$ & $\begin{array}{c}\text { Stasiun } \\
\text { III }\end{array}$ & Frekuensi(\%) \\
\hline 1 & ACB & + & + & + & 100 \\
2 & CM & + & + & + & 100 \\
3 & CF & + & + & + & 100 \\
4 & ACE & + & - & - & 33,3 \\
5 & CB & + & + & - & 66,6 \\
6 & CMR & + & + & - & 66,6 \\
\hline
\end{tabular}


Tabel 3. Komposisi jenis rekrutmen karang pada setiap stasiun

\begin{tabular}{|c|c|c|c|c|c|}
\hline \multirow{2}{*}{ Stasiun } & \multirow{2}{*}{$\begin{array}{c}\text { Bentuk } \\
\text { pertumbuhan } \\
\text { karang }\end{array}$} & \multicolumn{2}{|c|}{ Pengulangan } & \multirow{2}{*}{ Jumlah (Ni) } & \multirow{2}{*}{$\begin{array}{c}\mathrm{Pi}=\mathrm{ni} / \mathrm{N} \times \mathbf{1 0 0 \%} \\
(\%)\end{array}$} \\
\hline & & I & II & & \\
\hline \multirow{6}{*}{ I } & ACB & 3 & 4 & 7 & 17,5 \\
\hline & $\mathrm{CM}$ & 2 & 3 & 5 & 12,5 \\
\hline & $\mathrm{CF}$ & 3 & 9 & 12 & 30 \\
\hline & ACE & 2 & 4 & 6 & 15 \\
\hline & $\mathrm{CB}$ & 1 & 1 & 2 & 5 \\
\hline & CMR & 2 & 6 & 8 & 20 \\
\hline \multirow{5}{*}{ II } & $\mathrm{ACB}$ & 4 & 5 & 9 & 23,7 \\
\hline & $\mathrm{CM}$ & 7 & 4 & 11 & 27,5 \\
\hline & $\mathrm{CB}$ & 2 & 4 & 6 & 15,8 \\
\hline & CF & 3 & 3 & 6 & 15,8 \\
\hline & CMR & 4 & 2 & 6 & 15,8 \\
\hline \multirow{4}{*}{ III } & $\mathrm{CM}$ & 8 & 4 & 12 & 37,5 \\
\hline & $\mathrm{ACB}$ & 5 & 3 & 8 & 25 \\
\hline & $\mathrm{CB}$ & - & 2 & 2 & 6,25 \\
\hline & $\mathrm{CF}$ & 4 & 6 & 10 & 31,25 \\
\hline
\end{tabular}

Pada lokasi penelitian yang mempunyai komposisi jenis tertinggi terdapat pada bentuk pertumbuhan karang massive (CM) ini merupakan sebagai salah satu genus karang yang bereproduksi melalui mekanisme brooding dan telah memiliki septa dan endosimbion zooxanthellae yang berkontribusi sebagai penghasil energi bagi larva selama proses penempelan. Hal tersebut menyebabkan larva planula dari mekanisme brooding mampu langsung menempel pada substrat dan memiliki tingkat rekruitmen yang cenderung tinggi (Richmond, 2007).

Coral massive (CM) juga mampu memproduksi sebanyak 1905-2015 individu larva (Mate, 1997 dalam Pitasari, 2011) dibandingkan genera karang lain sehingga coral massive memiliki tingkat rekrutmen yang lebih tinggi (Moulding, 2005 dalam Pitasari, 2011). Insafitri et al. (2006) dan Bauman et al. (2015), menyebutkan jika coral massive juga dapat mentolelir terhadap banyak substrat seperti karang mati, pecahan karang dan pasir, selain itu coral massive juga mampu mentolerir kondisi lingkungan yang variatif.

Coral massive (CM) diketahui juga dapat hidup pada berbagai substrat baik pasir maupun pecahan karang pada kedalaman 3-8 meter (Tortotelo-Langarica et al. 2016; Subhan dan Afu, 2017). Hata et al., (2013), menyebutkan jika koloni karang yang mempunyai coral massive (CM) ditemukan melimpah pada substrat keras, sedangkan pada bentuk jenis karang dengan bentuk pertumbuhan branching komposisi jenisnya sedikit. Hal ini disebabkan oleh permukaan yang rata yang membuat arus dan sedimentasi langsung mengarah pada koloni sehingga dengan lifeform coral massive yang akan memiliki kepadatan lebih tinggi dan lebih dapat bertahan hidup dibanding dengan lifeform bercabang. Supriharyono (2000), menyebutkan jika bentuk pertumbuhan koloni karang dipengaruhi oleh berbagai faktor, salah satunya tekanan hidrodinamis yang berupa arus dan gelombang. Jackson (1977) menyatakan, koloni dengan lifeform coral massive memiliki ketahanan yang lebih besar terhadap arus, karena memiliki area yang lebih luas saat menempel pada substrat.

\section{Simpulan}

Dari hasil penelitian ini dapat disimpulkan sebagai berikut :

1. Terdapat 6 jenis rekruitmen karang berdasarkan bentuk pertumbuhan karang yang ditemukan di lokasi penelitian yaitu Coral mushroom (CMR), Coral Massive (CM), Coral Branching (CB), Acropora Branching (ACB), Coral folliose (CF) dan Coral Encrusting (ACE). 
2. Kepadatan rekruitmen karang berdasarkan bentuk pertumbuhan karang yang ditemukan penelitian yang terdapat pada stasiun I,II dan III rata-rata sebesar $0,55 \mathrm{ind} / \mathrm{m}^{2}$.

\section{Daftar Pustaka}

Abrar, M. 2005. Pemulihan populasi karang setelahpemutihan di perairan Sipora, KepulauanMentawai, Sumatera Barat. Widyariset, 8(1): 6072.

Acosta, A., F. D.Luisa., and P.Valeria. 2011. Review on hard coral recruitment (Cnidarian:Scleractian) in Columbia. Universitas Sciantiarum 16:200-218.

Bachtiar, I. 2002. Promoting recruitment of Scleractinian corals using artificial substrate in the Gili Indah, Lombok Barat, Indonesia. In: Moosa (Ed). Proc. of the Ninth In Coral Reef Symp ; Bali, 23-27 Oktober 2000. Jakarta: Menteri Lingkungan Hidup Republik Indonesia, LIPI dan ISRS: 425-430.

Bachtiar, I. And M. Abrar, A. Budiyanto. 2012. Rekrutmen Scleractinia di Perairan Lembata, Nusa Tenggara Timur. Indonesian Journal of Marine Science, 17 (1): 1-7.

Bauman. A. G., James. R. G., Glenn, D., Jeffery, L., Peter. A. T and Peter. D. S. 2015. Coral settlement on a highly disturbed equatorial reef system. PLoS ONE 10:1-19.

Erwin, P. M., Song, B. \& Szmant, A. M., (2008). Chemical effects of macroalgae

Hata, H., I. Hirabayashi., H. Hamaoka., Y. Mukai., K. Omori., H. Fukami. 2013. Species-diverse coral communities on an artificial substrat at a Tuna Farm in Amami, Japan. Marine Environmental Research 85:45-53.

Insafitri dan W.A Nugraha. 2006. Laju pertumbuhan karang Porites lutea. Ilmu Kelautan 11:50-53. 38

Jackson, J.B.C. 1977. Competition on marine substrata: the adaptive significance of solitary and colonial strategies. The American Naturalist 111: 743-767.

Munasik, Suharsono, J. Situmorang and H. N. Kamiso. 2008. Timing of larval release by reef coral Pocillopora damicornis at Panjang Island, Central Java. Marine Research in Indonesia, 33(1): 33-39.
Nontji, A. 1987. Laut Nusantara . Lembaga Oseanologi Nasional - LIPI,Djambatan, Jakarta

Pitasari, A., Aunurohim., dan D. Saptarini. 2011. Tingkat Rekrutmen Karang pada Tiga Tipe Substrat di Pantai Pasir Putih Situbondo. Skripsi. Surabaya:Program Pendidikan S1 Jurusan Biologi, Institut Teknologi Sepuluh Nopember.

Riegl B, Heine C, Branch GM. 1996. Function of Funnel-Shaped Coral Growth in A High Sedimentation Environment. Marine Ecology Progress Series(145): 87-93. [September 2013].

Richmond, R.H. 2007. Reproduction and Recruitment in Corals: Critical Links in The Persistence of Reefs in Life and Death of Coral Reefs. New York: Chapman and Hall.

Rudi, E. 2012. Pemutihan karang di Perairan Natuna bagian selatan Tahun 2010. Biospecies, 10 (1): 1-7.

Siringoringo, R. M. 2009. Potensi pemulihan komunitas karang setelah kejadian gempa dan tsunami di Pulau Nias, Sumatera Utara. Thesis (tidak dipublikasikan). Institut Pertanian Bogor. Bogor. $80 \mathrm{hlm}$.

Subhan, Afu LOA. 2017. Pengaruh laju sedimentasi terhadap rekrutmen karang di Teluk Kendari, Provinsi Sulawesi Tenggara. Jurnal Manusia dan Lingkungan, 24(2):73-80

Suharsono. 1995. Jenis - Jenis Karang Yang Umum Dijumpai Diperaiaran Indonesia. Pusat Penelitian dan pengembangan Oseanologi LIPI.Proyek Penelitian dan Pengembangan Daerah Pantai

Suharsono, 1984.Jenis-Jenis Karang yang Umum Dijumpai di Perairan Indonesia. P3-O LIPI, Proyek Penelitian dan Pengembangan Daerah Pantai, Jakarta.

Supriharyono, 2000. Pengelolaan Ekosistem Terumbu Karang. Djambatan: Jakarta.

Veron, J.E.N. 1995. The Biogeography and Evolution of the scleractinia. In Space and Time. UNSW Press.Sydney, Australia

Zakaria, I. J. 2004. On the growth of newly settled corals on concrete substrates in coral reefs of Pandan and Setan Islands, West Sumatera, Indonesia. $P h D$ (Dissertation). Kiel University Germany. 153 hlm. 